\title{
Analysis of Tensile Strength's Influence on Limit Height and Active Earth Pressure of Slope Based on Ultimate Strain Method
}

\author{
Jianping Xin, ${ }^{1}$ Yingren Zheng, ${ }^{1}$ Yingxiang $\mathrm{Wu}^{2}$ and $\mathrm{Abi} \mathrm{Erdi}^{3}$ \\ ${ }^{1}$ Department of Civil Engineering, Logistical Engineering University, Chongqing 401311, China \\ ${ }^{2} 69006$ Regiment of PLA, Urumqi 830002, China \\ ${ }^{3}$ School of River \& Ocean Engineering, Chongqing Jiaotong University, Chongqing 400074, China \\ Correspondence should be addressed to Jianping Xin; xinjp1987@126.com
}

Received 4 November 2016; Accepted 7 February 2017; Published 28 February 2017

Academic Editor: Katsuyuki Kida

Copyright (C) 2017 Jianping Xin et al. This is an open access article distributed under the Creative Commons Attribution License, which permits unrestricted use, distribution, and reproduction in any medium, provided the original work is properly cited.

\begin{abstract}
In the geotechnical engineering, the tensile failure of soil is disregarded for a long time. Actually, the tensile strength of soil is very low and the tensile failure really occurs, especially in the slope engineering. The limit height and active earth pressure of slope will change when considering the effect of tensile failure. In this paper, we try to figure out the limit height and active earth pressure of slope by using the new numerical limit analysis method, the ultimate strain method. The results, without considering tensile failure and with considering tensile failure, are compared with the analytical solutions. It is proved that the ultimate strain method is credible and feasible in the slope engineering. The result shows that the tensile strength has a great influence on the limit height of the unsupported slope, but little influence on supported slope. It also has obvious influence on the active earth pressure of supported slope when the value of tensile strength is small, and the smaller the tensile strength the larger the influence. But the earth pressure becomes stable when the value of tensile strength is over $10 \mathrm{kN}$, and it is much close to the one calculated without considering the tensile failure.
\end{abstract}

\section{Introduction}

Under shear-compression loading, the state of geotechnical materials firstly converts from the elastic into the plastic; then, after a period of full development, it finally converts into failure state. The yielding criterion can be used to judge whether the geomaterials enter the plasticity from the elasticity, but the yield does not mean failure. The failure happens only when the plastic fully develops and the failure criterion is satisfied. At present, there are not criteria of point failure or local failure for geomaterials, so we cannot know when and where the cracks will appear in geotechnical engineering, but the overall failure of geotechnical engineering can be determined by the limit analysis method. From the laboratory test or the engineering site, we can see that when the material enters the plastic state and develops to a certain extent, local cracks often occur in stress concentration region. With the load increases, cracks gradually extend until cut-through; in that case, the geotechnical engineering damages overall. It can be seen that the failure occurs after the plastic fully develops, beginning with point (local) failure; then local cracks appear. When cracks run through the engineering, the overall failure occurs [1-8].

In the numerical limit analysis, for the commonly used ideal elastic-plastic model, the yield stress and failure stress have the same value, so the stress cannot be used to judge whether the material is in the yield or failure state. But the yield strain and failure strain are different, so the strain can be used to determine whether the material is in the yield or failure state. Thus, the criterion of point failure can be expressed by strain. Based on this, a new numerical limit analysis method, ultimate strain method, is put forward.

The principle of ultimate strain method is that firstly the ultimate strain of geomaterials is obtained by numerical limit analysis; secondly the ultimate strain is taken as the criterion of point (local) failure for materials by setting its value as a dividing line when plotting the strain contour; when the strain is meeting the ultimate strain, the materials get failure; and then the location, shape, and evolution of failure plane are obtained. When the ultimate strain 


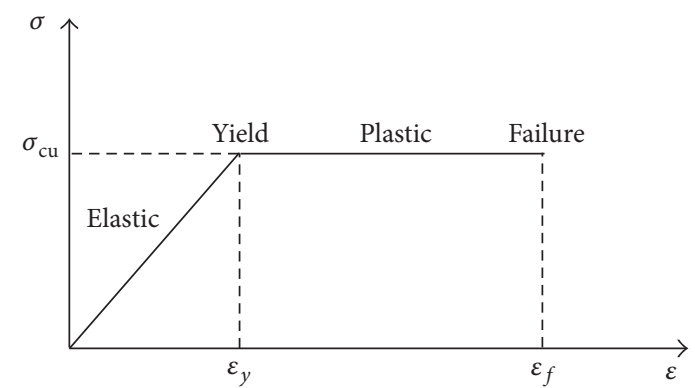

FIgURE 1: The ideal elastic-plastic stress-strain curve.

regions are run-through in the geotechnical engineering, the failure planes are run-through, which can be used as a criterion for the overall failure of geotechnical engineering, and the stability of geotechnical engineering can be analyzed [1].

This paper attempts to use the ultimate strain method to solve the limit height of vertical slope and the active earth pressure acting on the retaining wall. But for a long time, the tensile failure is disregarded in the two calculations. It is obvious that the tension failure has effect on the calculation results.

\section{Limit Height and Active Earth Pressure}

Solving the limit height of slope and solving the active earth pressure acting on the retaining wall are two classical computational problems of soil mechanics, which are closely related to the actual engineering. For a long time, the tensile failure is disregarded in the two calculations. In fact, the influence of considering soil's tensile failure on slope stability calculation cannot be ignored [1, 9-12]. In this paper, from the viewpoint of whether the tensile failure is considered, the limit height of the vertical slope and the active earth pressure are analyzed by using the ultimate strain method.

\section{The Concept and Calculation of Ultimate Strain}

The ultimate strain is the strain that is corresponding to the maximum stress point on the stress-strain curve, and the material will fail after reaching this point. Figure 1 is the stress-strain curve of the ideal elastic-plastic material. For the ideal elastic-plasticity, the stress has a linear relationship with the strain at the elastic stage. The strain reaches the elastic limit strain $\varepsilon_{y}$ just after reaching the yield point. The ideal plasticity is a horizontal straight line with constant stress, and strain continues to increase. When the plastic strain increases to a certain value, the material enters the development of damage, and this value of strain is the ultimate strain $\varepsilon_{f}$ [13-17].

The elastic strain and plastic strain relations under uniaxial condition are given in Abi et al.s paper [1]. The elastic strain formula of compressive strain and shear strain under uniaxial condition is

$$
\begin{aligned}
\varepsilon_{1 y} & =\frac{1}{E} \sigma_{1}=\frac{2 c \cos \varphi}{E(1-\sin \varphi)} \\
\sqrt{J_{2 y}^{\prime}} & =\frac{(1+\nu) \varepsilon_{1 y}}{\sqrt{3}}=\frac{2 c \cos \varphi(1+\nu)}{\sqrt{3} E(1-\sin \varphi)},
\end{aligned}
$$

where $\varepsilon_{1 y}$ is the elastic compressive strain and $\sqrt{J_{2 y}^{\prime}}$ is the elastic shear strain under uniaxial condition.

When the numerical method is used to calculate the ultimate strain, it is necessary to know the cohesion $c$, the internal friction angle $\varphi$, the elastic modulus $E$, Poisson's ratio $\nu$, and the tensile strength $\sigma_{t}$ of the geotechnical materials. The expression forms of shear strain used in different numerical analysis software are different and thus the limit strain values are also different but do not affect the analysis of soil failure state and the determination of safety factor, because in the same software, shear strain and ultimate strain are obtained from the same mechanical parameters. The FLAC3D software can directly display the shear strain increment contours, and the main failure of the slope is shear failure; therefore the ultimate strain used is the elastoplastic ultimate shear strain when calculating by FLAC3D in this paper [18]. The relationship between the elastoplastic shear strain and the principal strain under the uniaxial condition is

$$
\sqrt{J_{2}^{\prime}}=\frac{\varepsilon_{1}-\varepsilon_{3}}{\sqrt{3}}
$$

where $\sqrt{J_{2}^{\prime}}$ is the elastoplastic shear strain, $\varepsilon_{1}$ is the first principal strain, and $\varepsilon_{3}$ is the third principal strain under the uniaxial condition.

The following example shows, with FLAC3D software, how to get the material limit strain by using overloading method. Figure 2 shows two cube specimens with both $15 \mathrm{~cm}$ side lengths, which are used to simulate soils of whether the tensile strength is considered. Table 1 shows the mechanical parameters of the material. By applying increasing vertical uniform loads on the top, until the calculation does not converge, that means the specimen reaches the limit failure state. At this time, in specimen 1 (without consideration of tensile strength), the largest shear strain appears at the midpoint of the upper edge, but in specimen 2 (with consideration of tensile strength), the largest shear strain appears at the upper corner. And the whole failure happened in the both specimens, so the maximum shear strain on the upper side is considered as the ultimate shear strain of the material. Figures 2(a) and 2(b) show the shear strain contour of specimen 1 and specimen 2 , respectively. The ultimate shear strain of specimen 1 is $1.77 \%$ and the ultimate shear strain of specimen 2 is $1.07 \%$.

It should be noticed that the Mohr-Coulomb model in FLAC3D has a default tensile strength of 0 , so it is necessary to manually input a more realistic tensile strength when the tensile strength is to be considered. The reason for the difference of the failure between specimen 1 and specimen 2 is that the tensile strength of specimen 1 is 0 . 


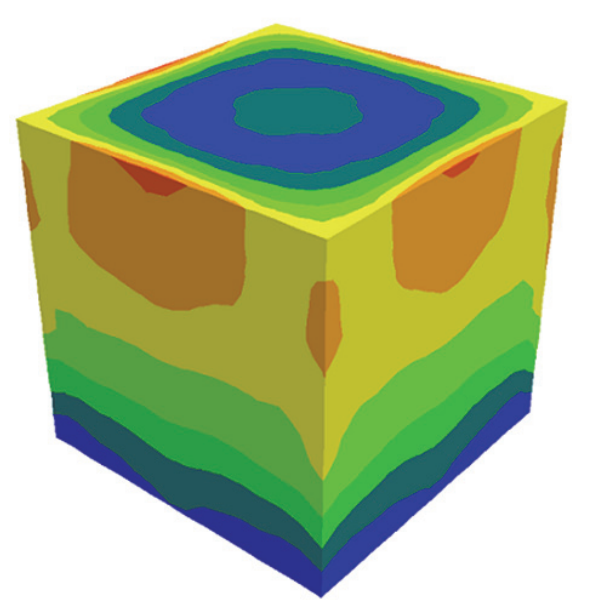

(a) Specimen 1

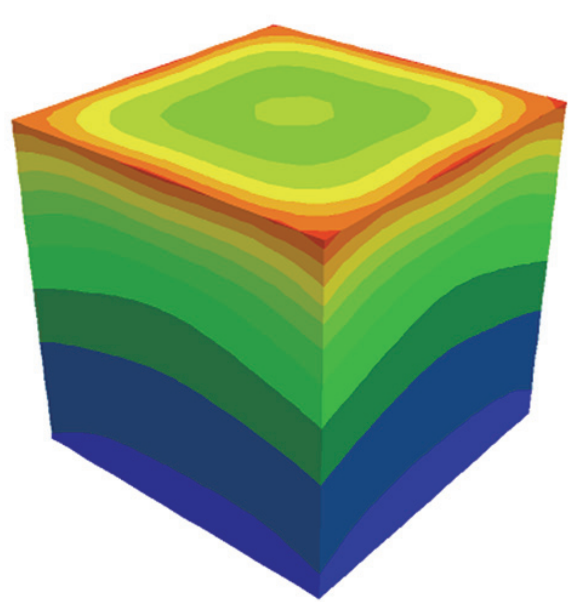

(b) Specimen 2

FIGURE 2: Contour of shear stain increment.

TABLE 1: Physical-mechanical parameters of material.

\begin{tabular}{lccccc}
\hline \multirow{2}{*}{ Specimen } & Elastic modulus $(\mathrm{MPa})$ & Poisson's ratio & Cohesion $(\mathrm{kPa})$ & Friction angle $\left(^{\circ}\right)$ & \multicolumn{2}{c}{ Tensile strength $(\mathrm{kPa})$} \\
& $E$ & $\nu$ & $c$ & $\sigma_{t}$ & 0 \\
\hline 1 & 10 & 0.30 & 40 & 20 & 20 \\
2 & 10 & 0.30 & 40 & 20 & 30 \\
\hline
\end{tabular}

TABLE 2: Contrast of limit heights from different methods.

\begin{tabular}{lcccc}
\hline & Formula (3) & Formula (4) & Formula (5) & Ultimate strain method \\
\hline Limit Height/m & 14.13 & 13.63 & 13.82 & 13.84 \\
Error/\% & 2.05 & 1.54 & 0.14 & - \\
\hline
\end{tabular}

\section{The Limit Height of the Slope}

4.1. Without Considering Tensile Failure. At present, when solving the slope's limit height by analytical solution method, it is default that the tensile failure is disregarded. But in fact, soil tensile failure occurs. It has certain influence on the limit height calculation of slopes whether the soil tensile failure is considered. The following example shows that the limit height of a vertical homogeneous soil slope is calculated by the formula and the ultimate strain method. The model parameters are as follows: weight $\gamma=20 \mathrm{kN} / \mathrm{m}^{3}, c=45 \mathrm{kPa}$, $\varphi=25^{\circ}, E=10 \mathrm{MPa}$, and $\nu=0.3$. Figure 3 shows the slope calculation model.

4.1.1. Analytical Method. According to Rankine theory of active earth pressure, the slip surface is assumed to be a straight line, and the formula is

$$
H_{\mathrm{cr}}=\frac{4 c}{\gamma} \tan \left(\frac{\pi}{4}+\frac{\varphi}{2}\right) ;
$$

the limit height of the vertical slope can be obtained as $14.13 \mathrm{~m}$ (Table 2). According to Chen [19], the given formula based on the energy law is

$$
H_{\mathrm{cr}}=\frac{3.858 c}{\gamma} \tan \left(\frac{\pi}{4}+\frac{\varphi}{2}\right) ;
$$

the limit height of the vertical slope is $13.63 \mathrm{~m}$ under the same conditions (Table 2). According to Dawson et al. [5], the limit height of the vertical slope is given by nonassociated flow law of the generalized plastic mechanics:

$$
H_{\mathrm{cr}}=\frac{3.913 c}{\gamma} \tan \left(\frac{\pi}{4}+\frac{\varphi}{2}\right) ;
$$

the limit height of the vertical slope under the above conditions is $13.82 \mathrm{~m}$ (Table 2). And the three analytical solutions are verified by the ultimate strain method in the following.

4.1.2. Ultimate Strain Method. During derivation of formulae (3), (4), and (5), the tensile strength is not considered; that is, the tensile failure of soil is disregarded, which is consistent 


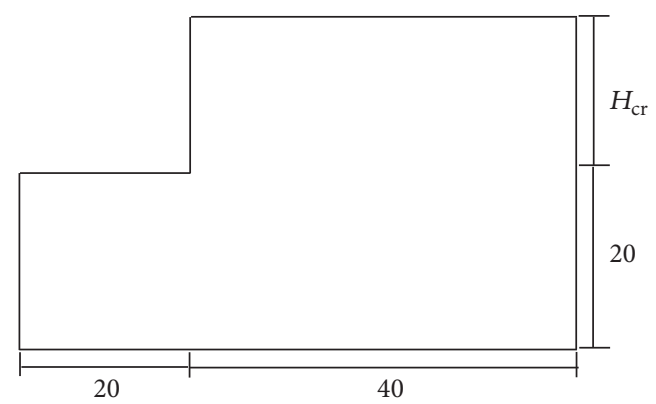

FIGURE 3: Calculation model of vertical slope (unit: m).

TABLE 3: Ultimate strain under the condition of different tensile strength.

\begin{tabular}{cccccc}
\hline$\sigma_{t} / \mathrm{kPa}$ & 0 & 1 & 10 & 15 & 25 \\
\hline$\sqrt{J_{2}^{\prime}} / \%$ & 2.15 & 0.82 & 0.81 & 0.80 & 0.79 \\
\hline
\end{tabular}

with the D-P criterion in ANSYS. Thus, ANSYS is used to calculate the slope by plane model. The ultimate equivalent plastic strain of this soil obtained is $10.5 \%$. Figure 4 shows the ultimate strain contours of the slope at different heights. Only the strain over the ultimate equivalent plastic strain is plotted in the contours and shown as red.

From Figure 4, it can be seen that the ultimate equivalent plastic strain zone (the red zone) is increasing with the slope height's increasing and extending from the slope foot to the top. When the height $H=13.70 \mathrm{~m}$, the ultimate equivalent plastic strain zone appears at the foot of the slope, which means that crack appears at this location. When $H=13.80 \mathrm{~m}$, the crack extends up to the middle of the slope. When $H=$ $13.83 \mathrm{~m}$, the crack almost extends to the top of the slope. When the height $H=13.84 \mathrm{~m}$, a run-through crack appears in the slope. Therefore, we consider $H=13.84 \mathrm{~m}$ as the limit height obtained without considering the tensile failure. From the above result, compared with results obtained by formulae (3), (4), and (5), there exist errors of $2.05 \%, 1.54 \%$, and $0.14 \%$, respectively, which indicates that formula (5) is more accurate, and the ultimate strain method is credible.

4.2. With Considering Tensile Failure. In the Mohr-Coulomb model of FLAC3D, the tensile failure is considered, and a true tensile strength value should be entered in the calculation to obtain a more accurate result. In the following calculation, the soil shear strength parameters and deformation parameters are fixed, but different tensile strength values are considered, and the limit heights of vertical slope under different tensile strength are determined by the ultimate strain method. Table 3 shows the ultimate shear strain with different tensile strength values. It can be seen that the ultimate shear strain is $2.15 \%$ with tensile strength $\sigma_{t}=0$ and the ultimate shear strain floats around $0.80 \%$ with $\sigma_{t}$ which varies from $1 \mathrm{kPa}$ to $25 \mathrm{kPa}$. This shows, in the numerical calculation, whether or not considering tensile strength has a large influence on the ultimate shear strain value, but the value of the tensile strength has little impact. In the following, the limit heights of
TABLE 4: Contrast of limit height under different tensile strength.

\begin{tabular}{ccccc}
\hline$\sigma_{t} / \mathrm{kPa}$ & 1 & 10 & 15 & 25 \\
\hline$H_{\mathrm{cr}} / \mathrm{m}$ & 10.09 & 12.33 & 12.89 & 13.57 \\
\hline
\end{tabular}

TABLE 5: Physical-mechanical parameters of materials.

\begin{tabular}{lcccccc}
\hline Material & $E / \mathrm{MPa}$ & $\nu$ & $\gamma / \mathrm{kN} \cdot \mathrm{m}^{-3}$ & $c / \mathrm{kPa}$ & $\varphi /{ }^{\circ}$ & $\sigma_{t} / \mathrm{kPa}$ \\
\hline Earth & 10 & 0.30 & 18 & 25 & 15 & Variables \\
Retaining wall & $1 e 4$ & 0.25 & 25 & - & - & - \\
\hline
\end{tabular}

vertical slope are calculated when $\sigma_{t}=1 \mathrm{kPa}, 10 \mathrm{kPa}, 15 \mathrm{kPa}$, and $25 \mathrm{kPa}$.

From Figure 5, it can be seen that the lower the tensile strength is, the closer the failure plane is to the surface. With the increasing of the tensile strength, the failure plane gradually extends to the interior of the slope. When $\sigma_{t}=$ $1 \mathrm{kPa}$, the failure plane extends from both the slope foot and top of the slope to the interior of the slope body, and the extension of the slope top is faster than that of the slope foot. When the tensile strength is larger, the fracture plane starts from the slope foot and extends upward until the top of slope damaged. As the tensile strength increases, the connection point of the fracture planes is closer to the top of slope. As can be seen from Table 4, the greater the tensile strength, the higher the slope's limit height. Therefore, when the shear strength is fixed, different tensile strength corresponds to different limit height.

\section{Rankine Active Earth Pressure}

5.1. Without Considering Tensile Failure. Earth pressure is dependent on the retaining wall. In order to calculate Rankine active earth pressure, a gravity retaining wall should be added to the vertical slope model, as shown in Figure 6. The retaining wall is considered as the ideal elastic material, and the physical-mechanical parameters of materials are shown in Table 5.

5.1.1. Analytical Method. In the calculation of Rankine soil pressure, the slip surface is assumed to be a straight line without considering the tensile failure of the soil. With considering the tensile effect between soil and the upper part of retaining structure, when retaining structure separates from soil, Rankine active earth pressure can be calculated as

$$
P=\frac{1}{2} \gamma H^{2} \tan ^{2}\left(\frac{\pi}{4}-\frac{\varphi}{2}\right)-2 c H \tan \left(\frac{\pi}{4}-\frac{\varphi}{2}\right)+\frac{2 c^{2}}{\gamma} .
$$

Without considering the tensile effect between soil and the upper part of retaining structure, when retaining structure does not separate from slope soil, Rankine active earth pressure can be calculated as

$$
P=\frac{1}{2} \gamma H^{2} \tan ^{2}\left(\frac{\pi}{4}-\frac{\varphi}{2}\right)-2 c H \tan \left(\frac{\pi}{4}-\frac{\varphi}{2}\right) .
$$

The result from formula (6) is $304.46 \mathrm{kN}$ and from formula (7) is $235.02 \mathrm{kN}$. 


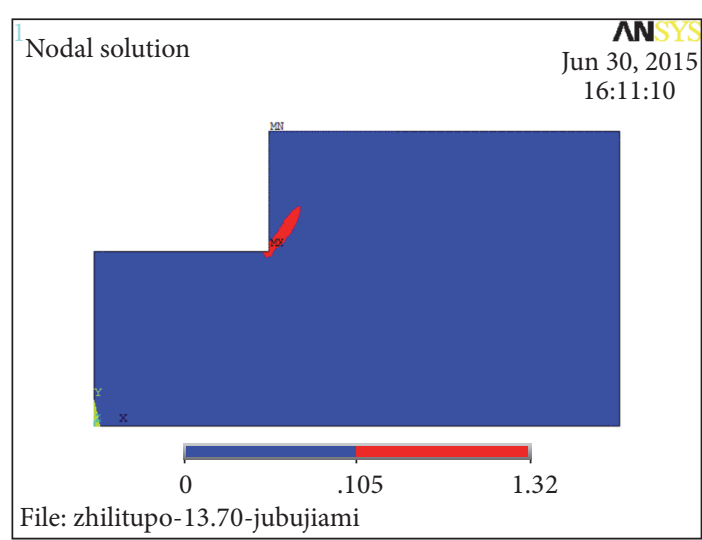

(a) $H=13.70 \mathrm{~m}$

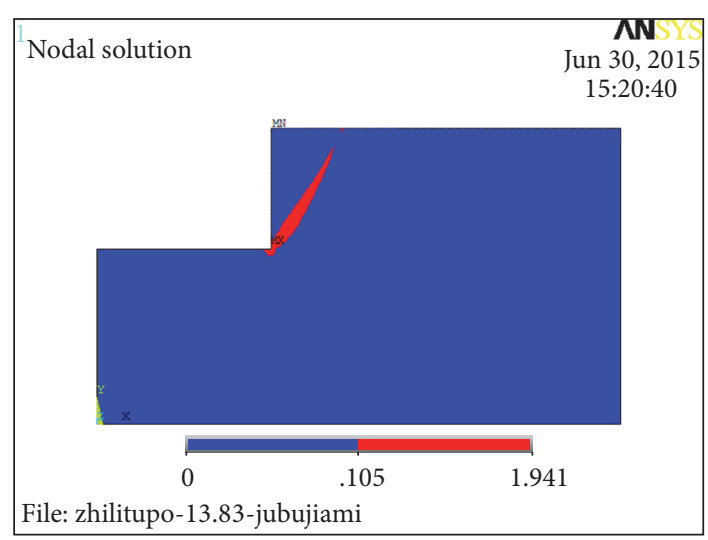

(c) $H=13.83 \mathrm{~m}$

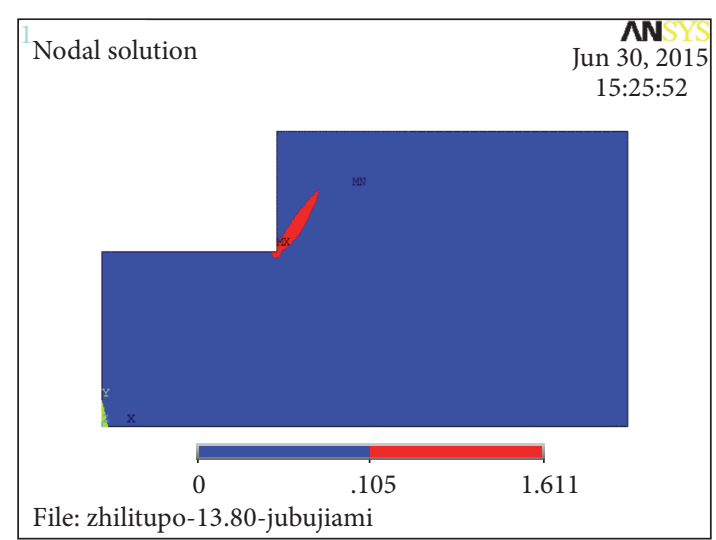

(b) $H=13.80 \mathrm{~m}$

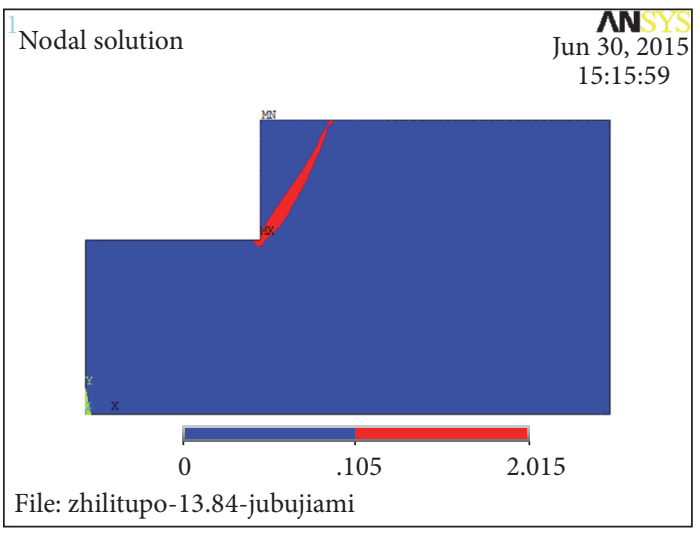

(d) $H=13.84 \mathrm{~m}$

FIGURE 4: Contour of ultimate equivalent plastic strain of slope at different heights (unit: $\mathrm{m}$ ).

5.1.2. Ultimate Strain Method. In the following, the active earth pressure is obtained by numerical limit analysis from two aspects, with considering tensile failure and without, which is compared with the Rankine active earth pressure calculated by formulae (6) and (7).

The ultimate strain of the soil is $5.04 \%$, which is calculated by ANSYS. When the height of the slope is $11.20 \mathrm{~m}$, the ultimate strain zone penetrates from the foot of the slope to the top of the slope, as Figure 7 shows the ultimate strain contour of the slope. It can be seen that the failure plane is curved. The $X$-direction stress of the inside retaining wall is extracted, and the earth pressure distribution is plotted in Figure 8. The maximum stress is at about one-quarter of the wall height and also is at about one-third of wall compression area. The tensile stress on the top of the wall is caused by wall-soil's common node in calculation model. The earth pressure on the retaining wall is obtained by integration of the compressive stresses in the compression zone. The earth pressure is $267.04 \mathrm{kN}$, which is $12.3 \%$ less than $304.46 \mathrm{kN}$ obtained by formula (6) and $13.6 \%$ more than $235.02 \mathrm{kN}$ obtained by formula (7).

5.2. With Considering Tensile Failure. FLAC3D is used to calculate under the conditions of considering tensile failure. The tensile strength is $2.5 \mathrm{kPa}, 5 \mathrm{kPa}, 7.5 \mathrm{kPa}, 10 \mathrm{kPa}, 12.5 \mathrm{kPa}$, and $15 \mathrm{kPa}$, respectively, and other parameters remain the same; the corresponding ultimate strain is $5.95 \%$, $5.92 \%$, $5.90 \%$, 5.89\%o, 5.88\%o, and 5.86\%o, respectively. Figure 9 shows the limit shear strain contour in the case of considering tensile failure. It can be seen that the location and shape of the failure plane are basically the same with those when the tensile failure is not considered. Figure 10 shows the distribution of active earth pressure of the slope under different tensile strengths. It can be seen that the distributions of earth pressure are basically the same, and the pressure areas are triangularly distributed, and the tensile stress is produced due to the wall-soil interaction, which is increasing with the tensile strength rises. The earth pressure on the retaining wall is obtained by integration of the compressive stresses in the compression zone, and the results are shown in Table 6.

It can be seen from Table 6 that, after building retaining wall, the limit height of the slope slightly increases with the tensile strength rising. When the tensile strength changes from $2.5 \mathrm{kPa}$ to $15 \mathrm{kPa}$, the limit height rises from $11.11 \mathrm{~m}$ to $11.25 \mathrm{~m}$. The active earth pressure also increases, and the numerical results are obviously smaller than those calculated by formula (6), but bigger than formula (7). $\Delta P_{1}$ and $\Delta P_{1} / P_{1}$ decrease firstly and then increase; the error varies from $21.7 \%$ to $13 \% . \Delta P_{2}$ and $\Delta P_{2} / P_{2}$ increase firstly and then decrease; the error varies from $2.1 \%$ to $12.3 \%$. Thus it can be seen that when 


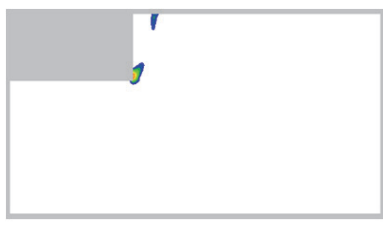

(A) $H=10.00 \mathrm{~m}$

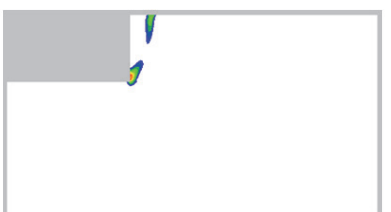

(B) $H=10.05 \mathrm{~m}$

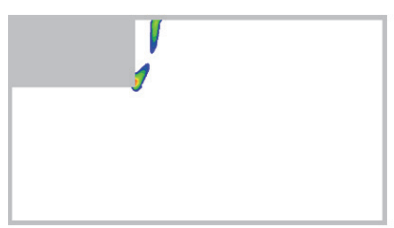

(C) $H=10.08 \mathrm{~m}$

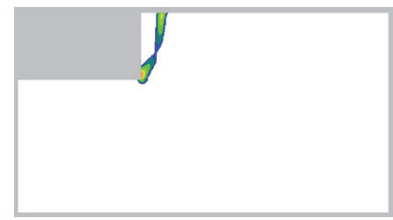

(D) $H=10.09 \mathrm{~m}$

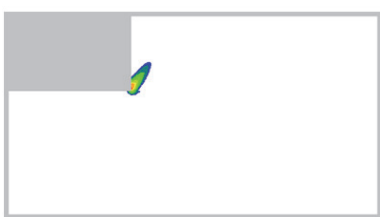

(A) $H=12.00 \mathrm{~m}$

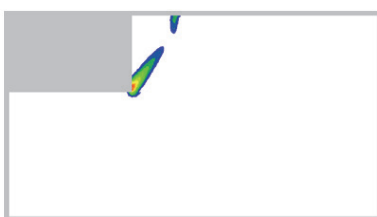

(B) $H=12.30 \mathrm{~m}$

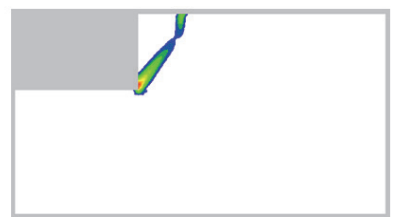

(C) $H=12.32 \mathrm{~m}$

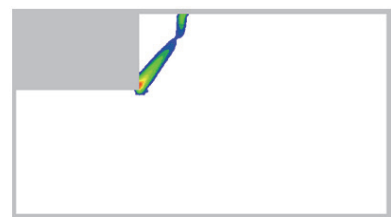

(D) $H=12.33 \mathrm{~m}$

(b) $\sigma_{t}=10 \mathrm{kPa}$

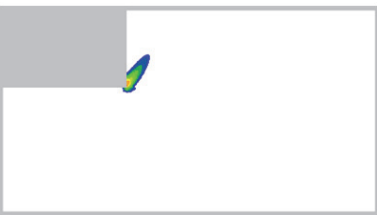

(A) $H=12.5 \mathrm{~m}$

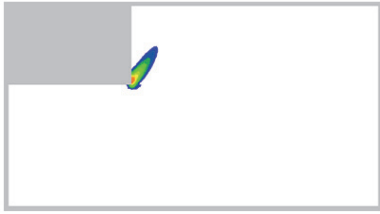

(A) $H=13.0 \mathrm{~m}$

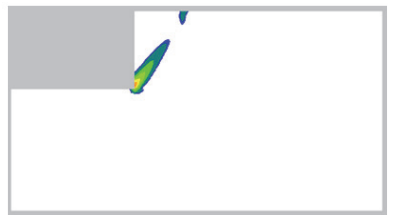

(B) $H=12.85 \mathrm{~m}$

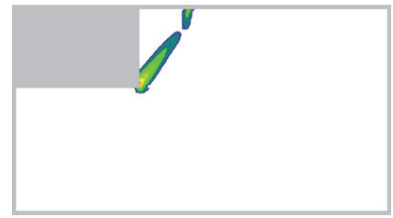

(C) $H=12.88 \mathrm{~m}$

(c) $\sigma_{t}=15 \mathrm{kPa}$

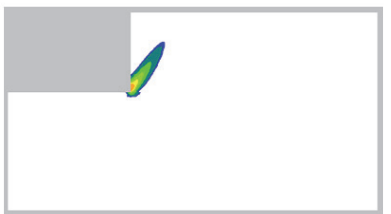

(B) $H=13.50 \mathrm{~m}$

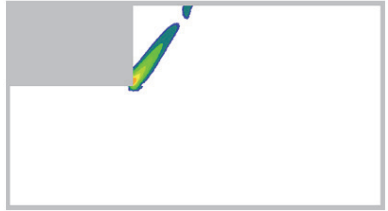

(C) $H=13.56 \mathrm{~m}$

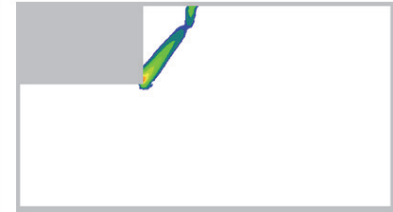

(D) $H=12.89 \mathrm{~m}$

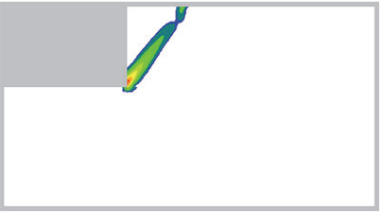

(D) $H=13.57 \mathrm{~m}$

(d) $\sigma_{t}=25 \mathrm{kPa}$

FIGURE 5: Contour of ultimate shear stain of slope slip at different tension strength (unit: $\mathrm{m}$ ).

TABLE 6: Limit height and active earth pressure under the condition of different tensile strength.

\begin{tabular}{|c|c|c|c|c|c|c|}
\hline Tensile strength $\sigma_{t} / \mathrm{kPa}$ & 2.5 & 5 & 7.5 & 10 & 12.5 & 15 \\
\hline Limit height $H_{\mathrm{cr}} / \mathrm{m}$ & 11.11 & 11.15 & 11.17 & 11.20 & 11.22 & 11.25 \\
\hline \multicolumn{7}{|l|}{ Earth pressure/kN } \\
\hline$P_{1}($ formula $(6))$ & 297.27 & 300.46 & 302.06 & 304.46 & 306.07 & 308.49 \\
\hline$P_{2}($ formula $(7))$ & 227.83 & 231.01 & 232.61 & 235.02 & 236.63 & 239.05 \\
\hline $\begin{array}{l}P_{n} \text { (ultimate strain } \\
\text { method) }\end{array}$ & 232.63 & 250.85 & 254.75 & 265.36 & 268.05 & 268.44 \\
\hline$\Delta P_{1} / \mathrm{kN}$ & 64.64 & 49.61 & 47.31 & 39.10 & 38.02 & 40.05 \\
\hline$\Delta P_{2} / \mathrm{kN}$ & 4.80 & 19.84 & 22.14 & 30.34 & 31.42 & 29.39 \\
\hline$\Delta P_{1} / P_{1}$ & $21.7 \%$ & $16.5 \%$ & $15.7 \%$ & $12.8 \%$ & $12.4 \%$ & $13.0 \%$ \\
\hline$\Delta P_{2} / P_{2}$ & $2.1 \%$ & $8.6 \%$ & $9.5 \%$ & $12.9 \%$ & $13.3 \%$ & $12.3 \%$ \\
\hline
\end{tabular}

Note. $\Delta P_{1}=P_{1}-P_{n} ; \Delta P_{2}=P_{n}-P_{2}$. 


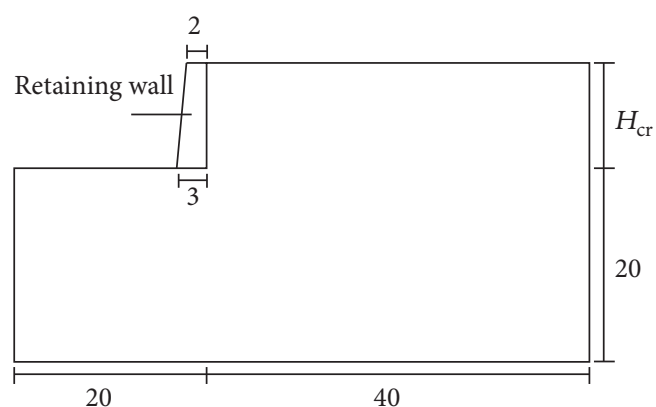

FIGURE 6: Calculation model of active earth pressure (unit: $\mathrm{m}$ ).

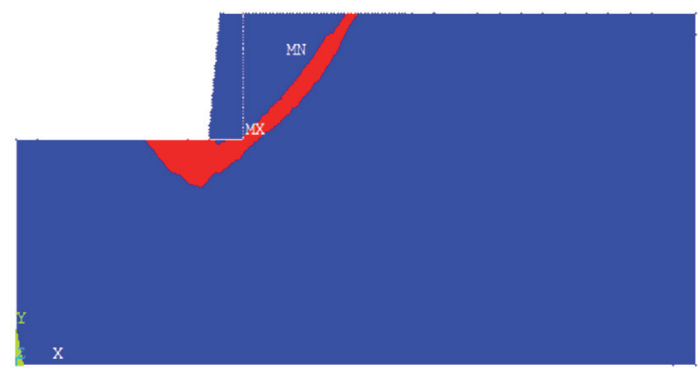

FIgURE 7: Contour of ultimate strain.

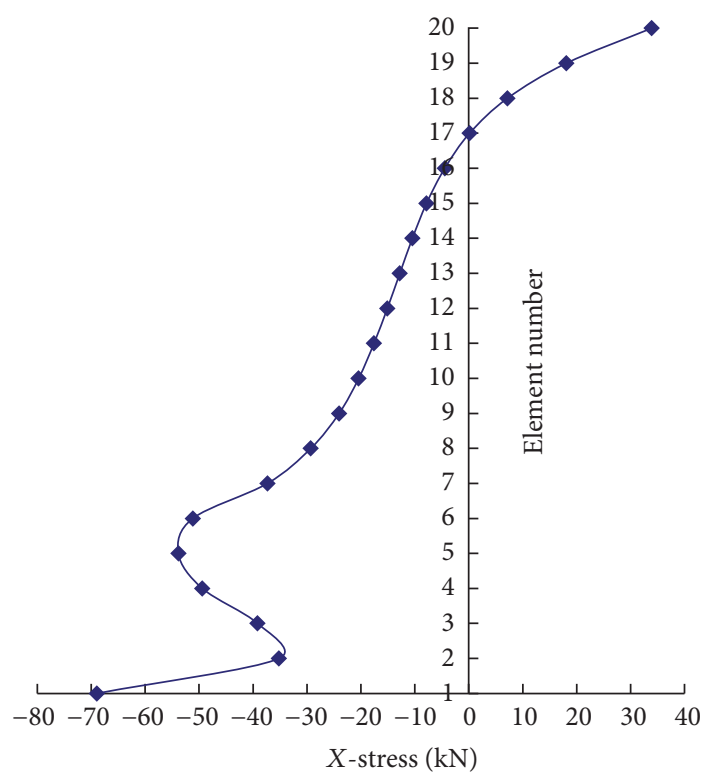

FIGURE 8: Distribution of earth pressure.

considering the soil's tensile failure, the smaller the tensile strength the smaller the error with formula (7). When the value of tensile strength is larger than $10 \mathrm{kPa}$, the active earth pressure obtained by FALC3D is very close to that obtained by ANSYS.

In summary, there are two cases for calculating the limit height and active earth pressure of slope: with or without considering the tensile failure of soil. The limit height and earth pressure are different under the above two different cases. In the absence of retaining structure, the limit height

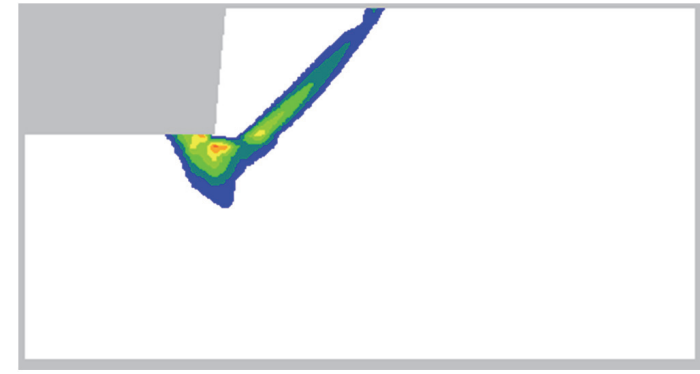

FIGURE 9: Contour of ultimate strain.

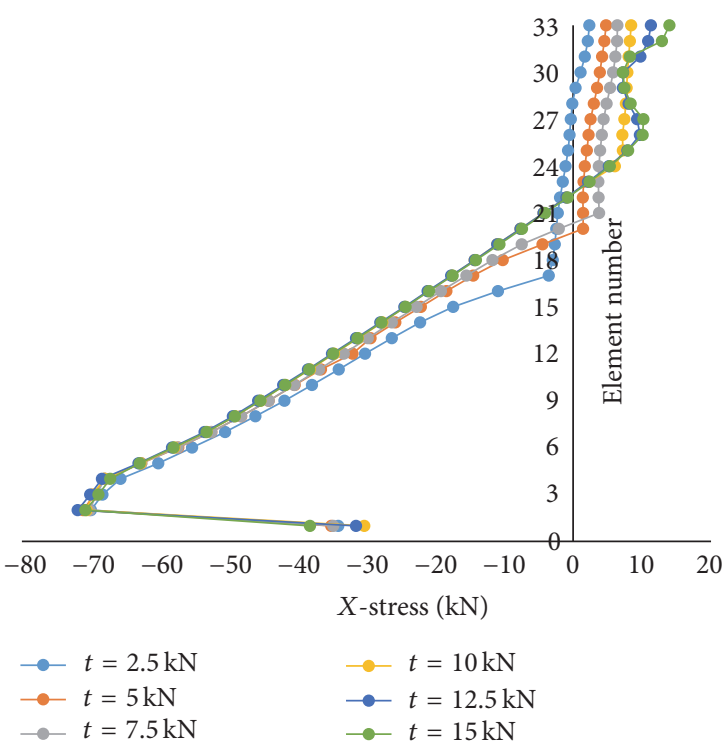

FIGURE 10: Distribution of earth pressure.

with considering tensile failure is obviously smaller than that without considering tensile failure, and the value of tensile strength has significant effect on the limit height. After adding the retaining structure, the effect decreases a lot under both conditions. The value of tensile strength also has effect on the active earth pressure; the smaller the tensile strength the closer the result of formula (7).

Therefore, it is necessary to pay attention to the deciding of the two cases when calculating the limit height of slope without retaining structure and the active earth pressure of slope with retaining structure. Generally, the soil has lower tensile strength, so the tensile failure should be considered in the calculation.

\section{Conclusion}

(1) The limit height and active earth pressure of vertical slope are obtained through the ultimate strain method. The analytical solutions are validated. The credibility and feasibility of the ultimate strain method are also proved. 
(2) The value of tensile strength has a significant influence on the limit height of unsupported slope but has little influence on the limit height of supported slope.

(3) The value of tensile strength also has obvious influence on the active earth pressure when the value of tensile strength is small, and the smaller the tensile strength the larger the influence. But the earth pressure becomes stable when the value of tensile strength is over $10 \mathrm{kN}$.

(4) The soil's tensile strength is very low, so the tensile failure should be considered in calculation.

\section{Competing Interests}

The authors declare that there is no conflict of interests regarding the publication of this paper.

\section{Acknowledgments}

This study was funded by the National Natural Science Foundation of China (no. 51378496) and Natural Science Foundation of Chongqing (no. cstc2016jcyjys0002).

\section{References}

[1] E. Abi, X. Feng, Y. Zheng, and J. Xin, "Strain analysis and numerical analysis based on limit strain for geomaterials," Chinese Journal of Rock Mechanics and Engineering, vol. 34, no. 8, pp. 1552-1560, 2015.

[2] Z. Yingren, Z. Hehua, F. Zhengchang et al., The Stability Analysis and Design Theory of Surrounding Rock of Underground Engineering, China Communications Press, Beijing, China, 2012.

[3] Z. Yingren and K. Liang, Geotechnical Plastic Mechanics, China Building Industry Press, Beijing, China, 2010.

[4] D. V. Griffiths and P. A. Lane, "Slope stability analysis by finite elements," Geotechnique, vol. 49, no. 3, pp. 387-403, 1999.

[5] E. M. Dawson, W. H. Roth, and A. Drescher, "Slope stability analysis by strength reduction," Geotechnique, vol. 49, no. 6, pp. 835-840, 1999.

[6] O. C. Zienkiewicz, C. Humpheson, and R. W. Lewis, "Associated and non-associated visco-plasticity and plasticity in soil mechanics," Geotechnique, vol. 25, no. 4, pp. 671-689, 1975.

[7] M. J. Roy, R. J. Klassen, and J. T. Wood, "Evolution of plastic strain during a flow forming process," Journal of Materials Processing Technology, vol. 209, no. 2, pp. 1018-1025, 2009.

[8] J. Polák, "Plastic strain-controlled short crack growth and fatigue life," International Journal of Fatigue, vol. 27, no. 10-12, pp. 1192-1201, 2005.

[9] J. Faleskog and I. Barsoum, "Tension-torsion fracture experiments-part I: experiments and a procedure to evaluate the equivalent plastic strain," International Journal of Solids and Structures, vol. 50, no. 25-26, pp. 4241-4257, 2013.

[10] Y. Zhou, T. Chen, J. Deng, H. Zheng, and Y. Cui, “Threedimensional stability analysis of slope regions based on strength reduction method," Electronic Journal of Geotechnical Engineering, vol. 20, no. 7, pp. 1689-1698, 2015.

[11] Y. Yang, Y. Wang, and Y. Wu, "The effect of variable modulus elastoplastic strength reduction method on slope stability,"
Electronic Journal of Geotechnical Engineering, vol. 20, no. 1, pp. 1-10, 2015.

[12] J. Xin, Z. Yingren, A. Erdi, and L. Wang, "Stability analysis by ultimate strain criterion in slope engineering," Electronic Journal of Geotechnical Engineering, vol. 21-24, pp. 7879-7905, 2016.

[13] J. Xin, Y. Zheng, X. Li, and B. Yang, "Exploration on safety assessment method based on strain for immersed tube tunnel," Electronic Journal of Geotechnical Engineering, vol. 21, pp. 67556770, 2016.

[14] S. Li, J. Xin, Y. Zheng, and X. Li, "Influence factors analysis and application of ultimate strain of geomaterials," Electronic Journal of Geotechnical Engineering, vol. 21, no. 22, pp. 6907-6919, 2016.

[15] Y. Zheng, S. Zhao, and C. Deng, "Development of finite element limit analysis method and its applications in geotechnical engineering," Engineering Science, vol. 8, no. 12, pp. 39-61, 2006.

[16] H. Zheng, "A three-dimensional rigorous method for stability analysis of landslides," Engineering Geology, vol. 144-145, pp. 3040, 2012.

[17] E. Abi, Y.-R. Zheng, X.-T. Feng, and Y.-Z. Xiang, "Analysis of circular tunnel stability based on the limit strain method," Applied Mathematics and Mechanics, vol. 36, no. 12, pp. 12651273, 2015 (Chinese).

[18] B. Liu and Y. Han, FLAC Theory Examples and Application Guide, China Communications Press, Beijing, China, 2005.

[19] W.-F. Chen, Limit Analysis and Soil Plasticity, J Ross Publishing, Plantation, Fla, USA, 2007. 

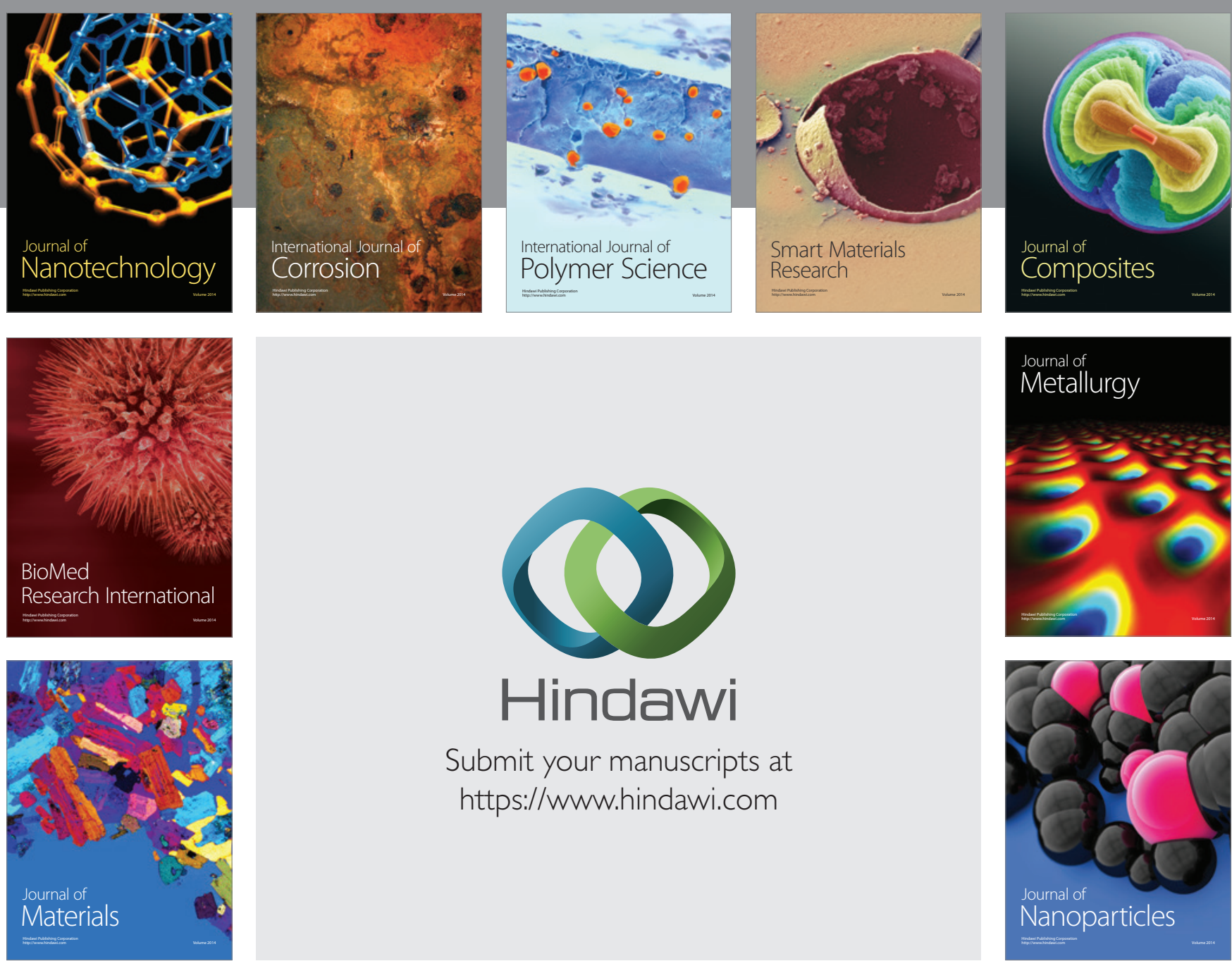

\section{Hindawi}

Submit your manuscripts at

https://www.hindawi.com

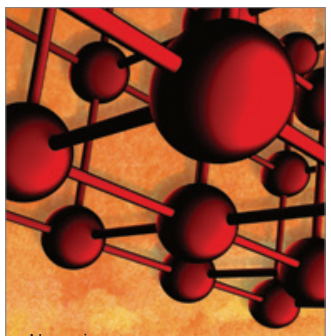

Materials Science and Engineering
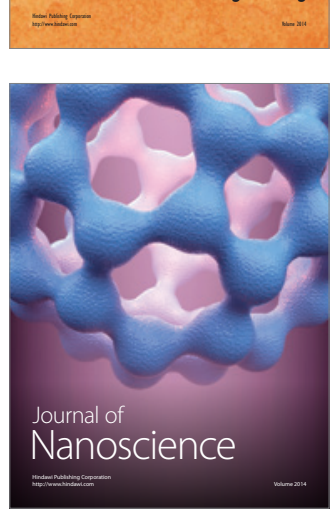
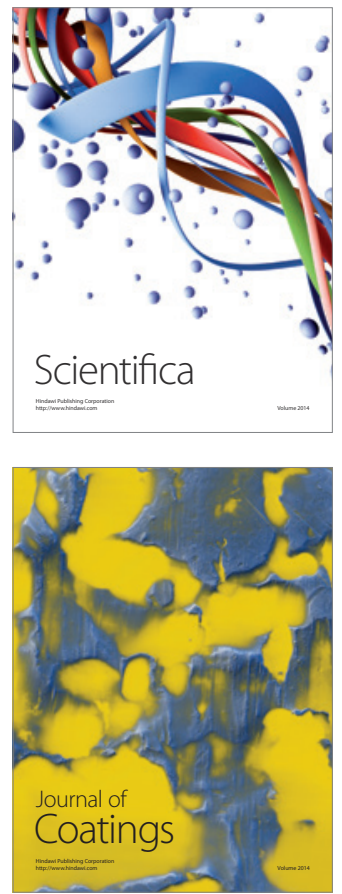
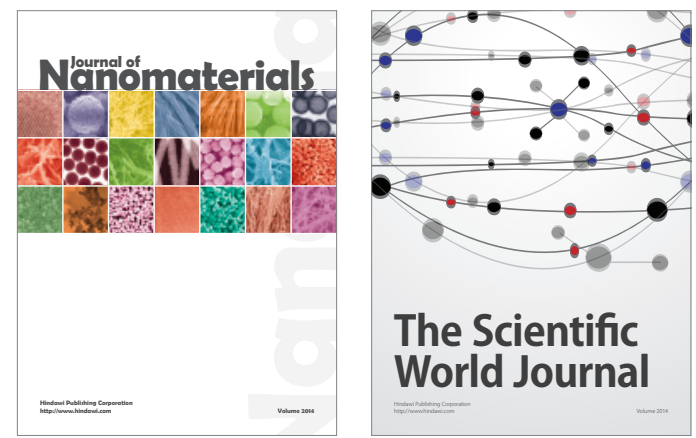

The Scientific World Journal
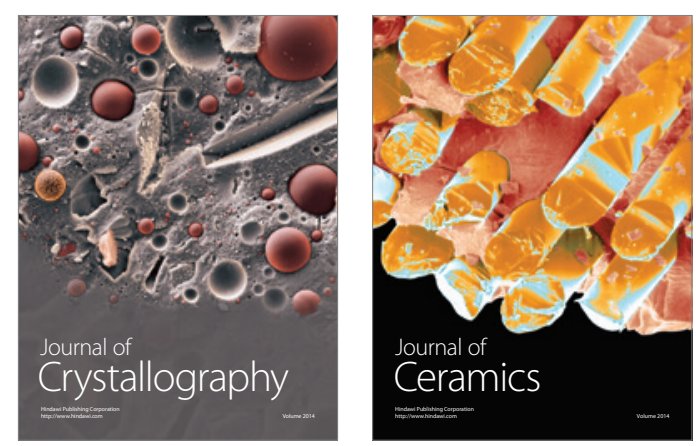
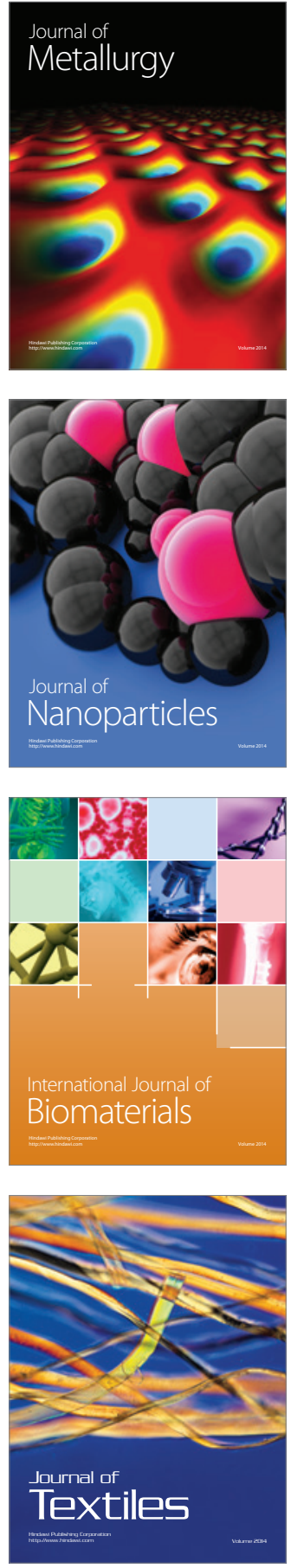